Edgar Jake A. Agullo, MD Emmanuel S. Samson, MD

Francisco A. Victoria, MD

Department of Otorhinolaryngology

Head and Neck Surgery

Ospital ng Maynila Medical Center
Correspondence: Dr. Francisco A. Victoria

Department of Otorhinolaryngology-Head and Neck Surgery

Ospital ng Maynila Medical Center

Quirino cor. Harrison Blvd.

Malate Manila 1004

Philippines

Phone: (632) 5246061 local 220

Email: ommc_enthns@yahoo.com

Reprints will not be available from the author

The authors declared that this represents original material that is not being considered for publication or has not been published or accepted for publication elsewhere in full or in part, in print or electronic media; that the manuscript has been read and approved by the authors, that the requirements for authorship have been met by the authors, and that the authors believe that the manuscript represents honest work.

Disclosures: The authors signed disclosures that there are no financial or other (including personal) relationships, intellectual passion, political or religious beliefs, and institutional affiliations that might lead to a conflict of interest.

Presented at the Poster Session Contest on Surgical Innovation \& Instrumentation (1st Place), Philippine Society of Otolaryngology-Head and Neck Surgery, Sofitel Philippine Plaza Hotel, CCP Complex, Manila, December 3, 2013.

\section{Animated Demonstration of Selected ORLHNS Concepts and Surgeries: A Potential Adjunct to Learning}

\begin{abstract}
Objective: To create visual animated demonstrations of certain otorhinolaryngologic concepts and surgeries that can aid learning of students and ORL residents.

Methods: Several otorhinolaryngologic surgical procedures and pathophysiologic concepts were represented through two dimensional images. For every concept or procedure, a series of images was drawn and manipulated using the software Adobe Photoshop CS4. The series of images were then put into animation using the software Morpheus Photo Animation Suite v3.15.
\end{abstract}

Result: The end results were demonstrations of otorhinolaryngologic concepts and surgical procedures in movie (.AVI) format.

Conclusion: Concepts and surgeries in the field of otorhinolaryngology are usually explained or documented using texts or simple images. The generated animated demonstration of these ideas can aid in the learning of the ORL specialist.

Keywords: animation, surgical procedure demonstration, pathophysiology animated presentation

It is difficult to contest that learning a task from scratch, that is if one has no prior knowledge regarding the matter is a very overwhelming mission. However, it is believed that humans rarely try to learn from nothing. They obtain initial ideas as well as strategies on how to approach a learning problem from instructions and/or demonstrations of other humans. ${ }^{1}$ Upon being introduced to a concept, the process of 'learning-by-doing' follows. This step is currently considered as the most effective way to learn. ${ }^{2}$ After this process, the learning is further reinforced through different methods such as repetition. ${ }^{3}$ This is probably the reason behind why most training institutions would have a minimum requirement of completed tasks before considering one individual as competent in doing such job.

Schaal' investigated how learning from demonstration can be applied in the context of reinforcement learning and concluded that reinforcement learning can theoretically profit from demonstrations. Using this concept, we aimed to create visual animated demonstrations of certain otorhinolaryngologic concepts and surgeries that can serve as a possible aid in the learning of students and ORL residents. Most concepts and procedures are explained in writing through textbooks and visual representations may potentially have a great impact on the absorption of knowledge by the learner.

This innovation did not test the actual degree of assistance that the animated representations would provide to a learner. It was solely based on the assumption that if one saw a visual representation of something explained in texts, it would be easier to comprehend. 


\section{SURGICAL INNOVATIONS AND INSTRUMENTATION}

\section{METHODS}

Several ORL surgical procedures and concepts were selected. Procedures included Z-plasty technique, rhomboid advancement flap, Abbe-Estlander flap, bilobe flap and cheiloplasty. Esophageal voice production for post laryngectomy patients and nystagmus were selected to represent the ORL concepts.

Two-dimensional images were rendered. These included multiple frames that would represent the succeeding steps in such processes. (Figure 1) These images were carefully adjusted and manipulated using the software Adobe Photoshop CS4 version 11.0 (San Jose, CA, USA: Adobe Systems Inc.). (Figure 2) Once all the steps were appropriately rendered, traditional animation was done. The images were allowed to animate using the software Morpheus Photo Animation Suite v3.15 Full (Ada, MI, USA: Morpheus Software, LLC). (Figure 3)

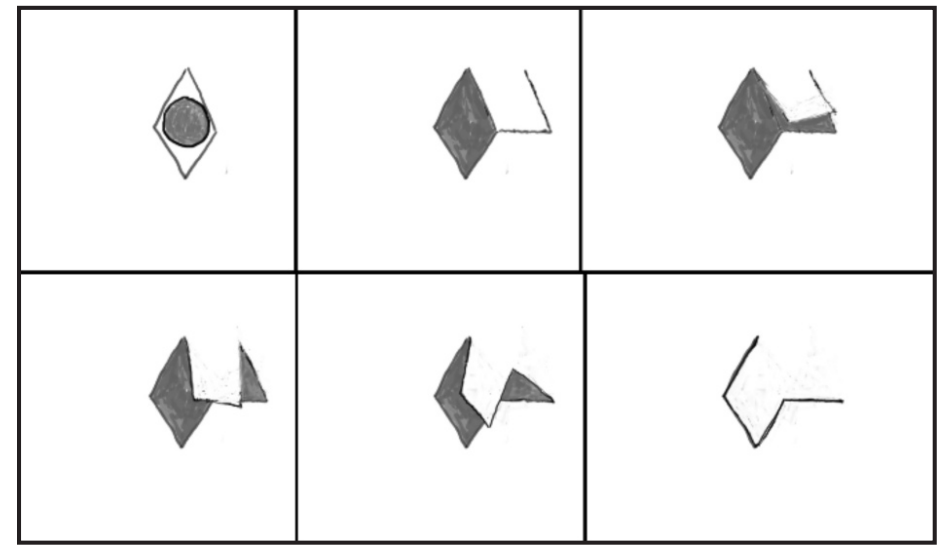

Figure 1. Sample series of images for the rhomboid flap

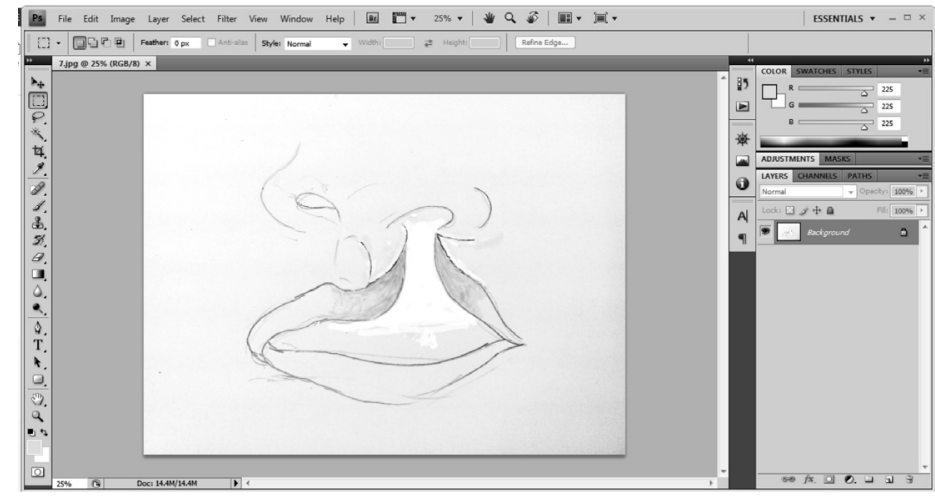

Figure 2. Screenshot showing image of cleft lip done on Adobe Photoshop CS4

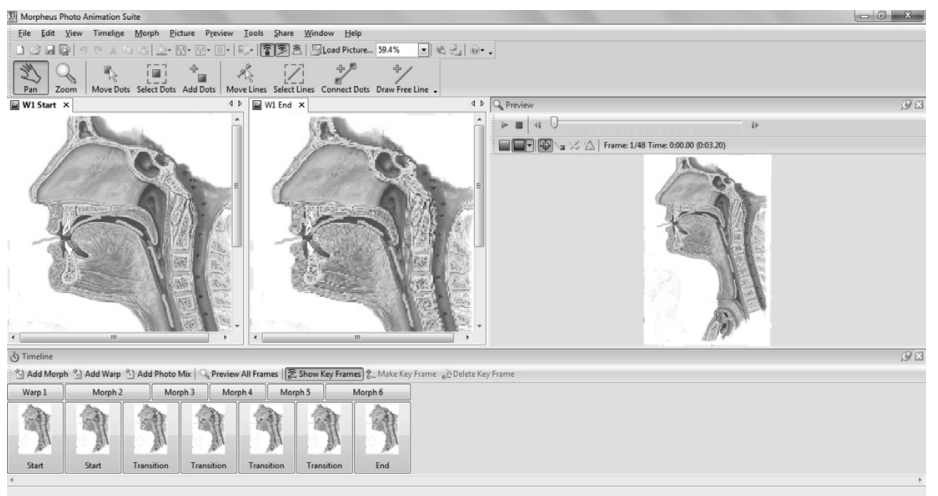

Figure 3. Screenshot showing rendition of animation using Morpheus Photo Animation Suite

\section{RESULTS}

Animated demonstrations of surgical procedures and concepts were produced. These were in the form of a movie (.AVI) file. These could be viewed using a regular media player through computers, tablets or modern television sets. A sample video clip in .mp4 format is available at: $h t t p: / / y o u t u . b e / 5 h w K P v 6 W 9 d Y$

\section{DISCUSSION}

Not every scientific idea or step in a surgical procedure is available as a visual presentation in textbooks. Much is explained in textual form and interpretation is left to the intellectual capacity of the reader. This may be one of the reasons why learning some concepts is challenging. Through rendering animated demonstrations, grasping the essence of scientific concepts and surgical procedures and thereby learning can be assisted. Our results need to be tested and the learning outcomes compared in order to establish their value and this may be the subject of a future study.

\section{REFERENCES}

Schaal S. "Learning from demonstration". In: Mozer MC, Jordan M, Petsche T, editors. Advances in Neural Information Processing Systems 9, Cambridge, MA: MIT Press. 1997. pp.1040-1046.

2. Lombardi MM. Authentic Learning for the $21^{\text {st }}$ Century: An Overview. Oblinger DG, editor. ELI Report No. 1. Boulder, CO: EDUCAUSE Learning Initiative. 2007 [cited 2013 Aug 23]. Available from: http://www.educause.edu/ir/library/pdf/ELI3009.pdf

3. Cunningham T, Gannon J, Kavanagh M, Greene J, Reddy L, Whitson L. Theories of learning and curriculum design-Key positionalities and their relationships. Articles. 2007:1 